\title{
Monitoring of the Intracranial Hemodynamics and Oxygenation during and after Hyperventilation in Newborn Rabbits with Near- Infrared Spectroscopy
}

\author{
ATSUSHI KAMEI, TAKEO OZAKI, AND SACHIO TAKASHIMA \\ Department of Pediatrics, Iwate Medical University, Mforioka, Japan [A.K.]; Division of Mental Retardation and \\ Birth Defect Research, National Institute of Neuroscience, NCNP, Tokyo, Japan [A.K., S.T.J; and Hamamatsu \\ Photonics, Hamamatsu, Japan [T.O.]
}

\begin{abstract}
Oxyhemoglobin, deoxyhemoglobin, total hemoglobin, and oxidized cytochrome $a a_{3}$ were monitored, blood pressure and heart rate were continuously recorded, and cerebral hemodynamic changes were analyzed during and after hyperventilation (arterial $\mathrm{CO}_{2}$ tension $<2.67$ $\mathrm{kPa})$ and/or hyperoxemia (100\% $\mathrm{O}_{2}$ inhalation) in 11- to 12-d-old rabbits. Oxyhemoglobin, deoxyhemoglobin, total hemoglobin, and oxidized cytochrome $a a_{3}$ were monitored by means of near-infrared spectroscopy. Near-infrared spectroscopy ideally demonstrated decreases in oxyhemoglobin and total hemoglobin and an increase in deoxyhemoglobin during hyperventilation and a return to the previous values after hyperventilation. Cytochrome $a a_{3}$ decreased during hyperventilation. On hyperventilation with $100 \% \mathrm{O}_{2}$ inhalation, however, cytochrome $a a_{3}$ was not reduced, although the changes in oxyhemoglobin and total hemoglobin were more significant. This reduction of cerebral oxygenation during hyperventilation without the administration of oxygen may induce hypoxic-ischemic brain damage. Noninvasive monitoring of cerebral oxygenation and hemodynamics, for which near-infrared spectroscopy is useful, is a requisite for the prevention of brain injury caused by severe hypocarbia in hyperventilation therapy, (Pediatr Res 35: 334-338, 1994)
\end{abstract}

\section{Abbreviations}

$\mathrm{HbO}_{2}$, cerebral oxyhemoglobin concentration

$\mathrm{HbR}$, cerebral deoxyhemoglobin concentration

HbT, total cerebral hemoglobin concentration

Cyt $a a_{3}$, cerebral oxidized cytochrome $a a_{3}$ concentration

NIRS, near-infrared spectroscopy

$\mathrm{PaCO}_{2}$, arterial $\mathrm{CO}_{2}$ tension

$\mathrm{PaO}_{2}$, arterial $\mathrm{O}_{2}$ tension

CBV, total cerebral blood volume

$\mathrm{CMRO}_{2}$, cerebral metabolic rate of oxygen

CBF, cerebral blood flow hypertension and asphyxia in many patients in neonatal intensive care units, concern has been raised as to how much decreased CBF during hyperventilation could cause cerebral hypoxia. Previous studies have demonstrated significant decreases in cerebral tissue $\mathrm{PO}_{2}$ during hyperventilation (6-8). However, inadvertent hypocarbia may occur when premature infants have mechanical ventilation for transport by ambulance from the place of birth to the neonatal intensive care unit because infants do not usually have any form of carbon dioxide monitoring during transport. In neonatal intensive care units, assisted ventilation is occasionally required for patients with relatively mild pulmonary damage (e.g. central apnea, mild respiratory distress after surfactant replacement therapy). Moreover, previous clinical and neuropathologic studies have suggested that hypocarbia is one of the important factors in the pathogenesis of leukomalacia (9), multicystic encephalomalacia (10), and pontosubicular necrosis (11) in neonates. In addition, there have been several reports that neurodevelopmental deficits may be caused by severe hypocarbia in preterm infants (12). Therefore, neonatologists must pay close attention to hypocarbia in such newborn infants. Continuous recording of intracranial oxygenation and hemodynamics during hyperventilation is important.

Noninvasive monitoring with NIRS provides continuous information on the intracranial hemodynamics, tissue oxygenation, and cell metabolism through measurement of $\mathrm{HbO}_{2}, \mathrm{HbR}$, $\mathrm{HbT}$, and Cyt $a a_{3}$, which is the terminal step in mitochondrial respiration $(13,14)$. This method was only recently applied in human neonatal care units $(15,16)$.

Rabbit brain, the rabbit being a rather immature species at birth, is a suitable neonatal model for measuring CBF (17). Histologically, the brains of 11 - to 12 -d-old newborn rabbits have a thin subependymal germinal layer and sparse myelination in the white matter of the cerebrum, and physiologically, immature electrical activity remains until 10 to $15 \mathrm{~d}$ after birth (18). Therefore, we regard these rabbits as being developmentally similar in maturity to human neonates.

The aim of this study is to clarify the dynamic changes in the cerebral circulation and oxygenation during hyperventilation in newborn rabbits with NIRS.

\section{MATERIALS AND METHODS}

Hypocarbia is a known depressant of CBF (1-5). Because hyperventilation is a common practice for persistent pulmonary

Received August 18, 1992; accepted October 20, 1993.

Correspondence: Atsushi Kamei, M.D., Department of Pediatrics, Iwate Medical University, Uchimaru, 19-1, Morioka 020, Japan.

Reprint requests: Sachio Takashima, M.D., Division of Mental Retardation and Birth Defect Research, National Institute of Neuroscience, NCNP, 4-1-1 Ogawahigashimachi, Kodaira, Tokyo 187, Japan.

Supported by grants from Ministry of Health and Welfare and the Ministry of Education, Japan.
Twenty-two newborn rabbits ( 11 to $12 \mathrm{~d}$ old), weighing $100-$ $180 \mathrm{~g}$, were anesthetized through inhalation of diethyl ether during all operative procedures. Tracheostomy and intubation were performed, and each rabbit underwent ventilation (Harvard Rodentventilator Model 683, Harvard Apparatus Co., Natick, MA). Pancronium bromide $(0.1-0.2 \mathrm{mg} / \mathrm{kg})$ was injected intraperitoneally to obtain paralysis. NIRS (NIR-1000, Hamamatsu 
Photonics KK, Hamamatsu Corp., Middlesex, NJ) monitoring was started at least $30 \mathrm{~min}$ after a steady heart rate and steady arterial blood pressure had been attained. Initially, the animals underwent ventilation at a rate of approximately 30 cycles $/ \mathrm{min}$. The arterial blood pressure and heart rate were continuously monitored through the femoral artery (San-ei Amplifier Case 7903 and Gould H.B. disposable pressure monitoring kit, Gould, Santa Clara, CA). Microsamples $(200 \mu \mathrm{L})$ of arterial blood were taken to measure the blood gas and hemoglobin concentrations (Ciba-Corning 288, Ciba-Geigy, Summit, NJ).

The concentration changes of $\mathrm{HbO}_{2}, \mathrm{HbR}, \mathrm{HbT}$, and Cyt $a a_{3}$ were continuously measured in 22 rabbits using NIRS, which involves near-infrared light at six wavelengths $(780,808,830$, 847,867 , and $911 \mathrm{~nm}$ ). A flexible fiberoptic bundle conveyed the near-infrared light from laser diodes to the head. The end of the fiber bundle (the optode) was applied to the scalp. The interoptode distance was $2.5 \mathrm{~cm}$, which was fixed in all experiments. The room lights were turned off, and monitoring was performed in a dark room. In this study, changes in $\mathrm{HbO}_{2}, \mathrm{HbR}$, $\mathrm{HbT}$, and Cyt $a a_{3}$ were expressed as relative variation because we could not determine the optical path length.

The rabbits were divided into four groups: group $\mathrm{HV}, \mathrm{HO}$, $\mathrm{HH}$, and $\mathrm{C}$. In group $\mathrm{HV}$, after the first blood sampling for blood gas analysis and hemoglobin concentration measurement and after baseline values determination in a normoxic and normocarbic steady state for at least $30 \mathrm{~min}$, hyperventilation was started at a rate of approximately 80 cycles $/ \mathrm{min}$ with a fixed tidal volume to produce hypocarbia of below $2.67 \mathrm{kPa} \mathrm{PaCO}_{2}$. The second blood sampling was performed in a normoxic and hypocarbic steady state for at least $30 \mathrm{~min}$, and then the hyperventilation was stopped. Thereafter, the third measurement was performed in a normoxic and normocarbic steady state for at least $30 \mathrm{~min}$. In group $\mathrm{HO}$, hyperoxia was induced by $100 \% \mathrm{O}_{2}$ inhalation, and the second measurement was performed in a hyperoxic and normocarbic steady state for at least $30 \mathrm{~min}$. In group $\mathrm{HH}$ with hyperventilation with hyperoxia, the second measurement was performed in a hyperoxic and hypocarbic steady state for at least $30 \mathrm{~min}$. The first and third measurements were performed in the same state as in group HV. Group C served as normoxic and normocarbic controls to assess the stability of this animal preparation. They were treated in a similar manner as the experimental groups but had no loading.

The results are presented as mean values \pm SD. Statistical analysis of the mean blood pressure, hemoglobin concentration, and arterial blood gas data was performed by means of $t$ test. The Mann-Whitney $U$ test was also used in statistical analysis of the NIRS data.

\section{RESULTS}

Table 1 shows an outline of the data for the heart rate, mean arterial pressure, blood $\mathrm{Hb}$, and blood gas analysis before, during, and after the experimental loading in each group. There were significantly higher $\mathrm{pH}$ and lower $\mathrm{PaCO}_{2}$ values during hyperventilation in groups $\mathrm{HV}\left(\mathrm{pH} 7.711 \pm 0.059, \mathrm{PaCO}_{2} 1.76 \pm 0.29\right.$ $\mathrm{kPa})$ and $\mathrm{HH}\left(\mathrm{pH} 7.750 \pm 0.024, \mathrm{PaCO}_{2} 1.69 \pm 0.27 \mathrm{kPa}\right)$, and higher $\mathrm{PaO}_{2}$ values during $100 \% \mathrm{O}_{2}$ inhalation in groups $\mathrm{HO}$ $\left(\mathrm{PaO}_{2} 38.19 \pm 7.20 \mathrm{kPa}\right)$ and $\mathrm{HH}\left(\mathrm{PaO}_{2} 33.65 \pm 8.67 \mathrm{kPa}\right)$ than in the control group. The mean arterial blood pressure did not show a significant difference at any time between any of the experimental and control groups, although it was lower during than before hyperventilation in group $\mathrm{HV}$. Blood gas analysis also did not reveal significant difference at any time after loading between the experimental and control groups.

Figure 1 presents typical NIRS data for each experiment. An obvious difference exists between hyperventilation $(A)$, and hyperventilation with $100 \% \mathrm{O}_{2}$ inhalation $(C)$ in that there is no reduction during hyperventilation with $100 \% \mathrm{O}_{2}$ inhalation, although the reduced state of cytochrome oxidase is observed during hyperventilation.
Figure 2 shows changes in the concentrations of $\mathrm{HbO}_{2}, \mathrm{HbR}$, $\mathrm{HbT}$, and Cyt $a a_{3}$. In group $\mathrm{HV}, \mathrm{HbO}_{2}$ decreased with the passage of time during hyperventilation, and the reduction persisted after loading. HbR increased with time during hyperventilation and gradually recovered to within normal range after hyperventilation. $\mathrm{HbT}$ showed a pattern similar to $\mathrm{HbO}_{2}$. Cyt $a a_{3}$ also decreased during hyperventilation but after that gradually increased to within normal range. In group $\mathrm{HO}, \mathrm{HbO}_{2}$ slightly increased during $100 \% \mathrm{O}_{2}$ inhalation, but the increase was not statistically significant. $\mathrm{HbR}$ markedly decreased during loading and after that rapidly increased to the preloading level. HbT showed a tendency to decrease, but Cyt $a a_{3}$ did not show any changes during or after $100 \% \mathrm{O}_{2}$ loading. In group $\mathrm{HH}$, $\mathrm{HbO}_{2}$ and $\mathrm{HbT}$ decreased during loading and then increased. The reduction of HbT was more significant in group $\mathrm{HH}$. However, HbR was slightly increased during loading and continued to increase after the loading. The oxygenation of $\mathrm{Cyt} a a_{3}$ remained in the control range.

\section{DISCUSSION}

This study demonstrated that passive hyperventilation causes gradual reductions of $\mathrm{HbO}_{2}, \mathrm{HbT}$, and Cyt $\mathrm{aa}_{3}$ and an increase in $\mathrm{HbR}$, although systemic oxygenation remains within normal range. However, hyperventilation with $100 \% \mathrm{O}_{2}$ inhalation does not cause any reduction of $\mathrm{Cyt} a a_{3}$ despite marked reduction of $\mathrm{HbO}_{2}$ and $\mathrm{HbT}$. The $100 \% \mathrm{O}_{2}$ inhalation causes decreases in $\mathrm{HbR}$ and $\mathrm{HbT}$ and a slight increase in $\mathrm{HbO}_{2}$ but no change in Cyt $a a_{3}$. Because HbT reflects CBV (16), hypocarbia and hyperoxemia cause the reduction of $\mathrm{CBV}$.

Although hypocarbia and hyperoxemia cause a decrease in $\mathrm{CBF}$, the $\mathrm{CBF}$ response varies depending on the levels of hypocarbia, systemic oxygenation, and loss of cerebral pressure-flow autoregulation in brain damage, and the maturity of the animals. The decrease in CBF during passive hyperventilation was $36 \%$ in human adults $\left(\mathrm{PaCO}_{2} 5.73\right.$ to $\left.3.07 \mathrm{kPa}\right)(4), 40 \%$ in the cerebrum of newborn piglets $\left(\mathrm{PaCO}_{2}\right.$ range of $\left.<2.0 \mathrm{kPa}\right)(3)$, and $51 \%\left(\mathrm{PaCO}_{2} 5.33\right.$ to $\left.3.33 \mathrm{kPa}\right)$ and $69 \%\left(\mathrm{PaCO}_{2} 5.33\right.$ to $\left.2.0 \mathrm{kPa}\right)$ in the cerebral gray matter of a newborn dog (2). On the other hand, the changes in CBF with $100 \% \mathrm{O}_{2}$ inhalation are in general agreement with the study by Kennedy et al. (19), which involved the ${ }^{14} \mathrm{C}$-antipyrine autoradiographic method in newborn dogs. They showed that $100 \% \mathrm{O}_{2}$ lowered $\mathrm{CBF}$ by $25 \%$ in 2 -d-old beagle puppies, but at $3 \mathrm{wk}$ of age the effect was much less (13\%). A decrease of $15 \%$ in CBF has also been reported in human adults and preterm infants $(20,21)$.

The relationship between the decrease in CBF and cerebral biochemical metabolism during hyperventilation is complex. Severe hypocarbia has been found to increase the lactate concentration in cerebral tissue and cerebrospinal fluid $(6,7,22)$. It is uncertain whether this increase is due to mild tissue hypoxia or alkalosis-induced activation of the phosphofructokinase pathway, which is unrelated to hypoxia (23). Controversy exists as to whether the production of lactate is a result of anaerobic glycolysis. Reuter and Disney (2) observed that severe hypocarbia in newborn dogs causes a $15 \%$ decrease in $\mathrm{CMRO}_{2}$. In another study, newborn piglets exhibited a decrease in $\mathrm{CMRO}_{2}$ after 30 min of hyperventilation (24). This evidence suggests that the decrease in $\mathrm{CMRO}_{2}$ during respiratory alkalosis might be caused by a decrease in cerebral oxygen demand and an increase in anaerobic glycolysis against cerebral hypoxia. However, studies on both adult animals and human beings suggest that $\mathrm{CMRO}_{2}$ is maintained at a constant level during severe hypocarbia $(4,5)$. Therefore, neonatal cerebral metabolism in hypocarbia may differ from that in adults. In addition, several biochemical and 31 -phosphorus magnetic resonance spectroscopic $(22,25)$ studies did not demonstrate any change in the ATP or phosphocreatine level during hyperventilation in adults. However, in newborn piglets, profound tissue hypoxia with membrane insufficiency 
Table 1. Changes in heart rate, mean arterial blood pressure, Hb concentration, and arterial blood gas analysis before, during, and after hyperventilation, hyperoxemia, and hyperventilation with hyperoxemia, with NIRS and in controls*

\begin{tabular}{|c|c|c|c|c|c|c|c|c|}
\hline & $n$ & HR (bpm) & MAP $(\mathrm{mm} \mathrm{Hg})$ & $\mathrm{Hb}(\mathrm{g} / \mathrm{L})$ & $\mathrm{pH}$ & $\mathrm{PaCO}_{2}(\mathrm{kPa})$ & $\mathrm{PaO}_{2}(\mathrm{kPa})$ & $\mathrm{HCO}_{3}(\mathrm{mmol} / \mathrm{dL})$ \\
\hline \multicolumn{9}{|l|}{ Before } \\
\hline HV-nir & 7 & $363.4 \pm 19.2$ & $55.4 \pm 6.4$ & $118 \pm 15$ & $7.425 \pm 0.037$ & $4.85 \pm 0.51$ & $17.00 \pm 4.45$ & $23.8 \pm 1.3$ \\
\hline HO-nir & 5 & $369.0 \pm 18.2$ & $46.6 \pm 8.0$ & $125 \pm 23$ & $7.490 \pm 0.050$ & $4.37 \pm 0.72$ & $16.19 \pm 4.20$ & $24.7 \pm 2.9$ \\
\hline HH-nir & 5 & $347.4 \pm 30.5$ & $49.8 \pm 6.6$ & $126 \pm 15$ & $7.460 \pm 0.031$ & $4.45 \pm 0.55$ & $18.49 \pm 3.15$ & $23.6 \pm 1.7$ \\
\hline C & 5 & $345.4 \pm 37.2$ & $51.0 \pm 5.7$ & $104 \pm 22$ & $7.457 \pm 0.036$ & $4.33 \pm 0.64$ & $19.48 \pm 2.12$ & $22.9 \pm 2.7$ \\
\hline \multicolumn{9}{|l|}{ During } \\
\hline HV-nir & 7 & $346.3 \pm 21.3$ & $45.1 \pm 6.6 \dagger$ & $111 \pm 14$ & $7.711 \pm 0.059 \dagger \ddagger$ & $1.76 \pm 0.29 \dagger \ddagger$ & $20.90 \pm 1.00$ & $16.5 \pm 1.3 \dagger \ddagger$ \\
\hline HO-nir & 5 & $370.0 \pm 25.4$ & $46.0 \pm 8.2$ & $124 \pm 24$ & $7.510 \pm 0.058$ & $4.17 \pm 0.63$ & $38.19 \pm 7.20 \dagger \ddagger$ & $24.8 \pm 2.2$ \\
\hline HH-nir & 5 & $337.4 \pm 38.0$ & $41.6 \pm 7.3$ & $126 \pm 10$ & $7.750 \pm 0.024 \nmid \ddagger$ & $1.69 \pm 0.27 \dagger \ddagger$ & $33.65 \pm 8.67 \dagger \ddagger$ & $17.6 \pm 2.4 t \ddagger$ \\
\hline C & 5 & $353.8 \pm 32.1$ & $47.2 \pm 6.8$ & $100 \pm 29$ & $7.502 \pm 0.046$ & $4.07 \pm 0.56$ & $19.03 \pm 2.93$ & $23.9 \pm 3.1$ \\
\hline \multicolumn{9}{|l|}{ After } \\
\hline HV-nir & 7 & $356.6 \pm 24.7$ & $51.3 \pm 6.8$ & $107 \pm 13 \dagger$ & $7.428 \pm 0.030$ & $4.36 \pm 0.41 \dagger$ & $13.61 \pm 3.59$ & $21.5 \pm 0.9 \dagger$ \\
\hline HO-nir & 5 & $358.0 \pm 19.2$ & $45.2 \pm 6.6$ & $115 \pm 22$ & $7.467 \pm 0.046$ & $4.47 \pm 0.85$ & $13.76 \pm 4.00$ & $24.0 \pm 2.2$ \\
\hline HH-nir & 5 & $335.2 \pm 27.2$ & $46.0 \pm 6.5$ & $119 \pm 12$ & $7.479 \pm 0.044$ & $3.93 \pm 0.45$ & $16.33 \pm 3.41$ & $21.9 \pm 2.1$ \\
\hline $\mathrm{C}$ & 5 & $35 \mathrm{I} .2 \pm 38.3$ & $48.0 \pm 10.6$ & $98 \pm 22$ & $7.503 \pm 0.054$ & $4.08 \pm 0.44$ & $17.33 \pm 3.20$ & $24.0 \pm 2.9$ \\
\hline
\end{tabular}

* Values are means $\pm \mathrm{SD}$. HR, heart rate; MAP, mean arterial blood pressure; $\mathrm{HCO}_{3}$, bicarbonate ion; HV-nir, hyperventilation; HO-nir, hyperoxemia; $\mathrm{HH}$-nir, hyperventilation with hyperoxemia: $\mathrm{C}$, controls.

+ Significantly lower than the preceding value; $p<0.01$, paired $t$ test.

$\ddagger$ Significantly lower than the control value: $p<0.01$, unpaired $t$ test.
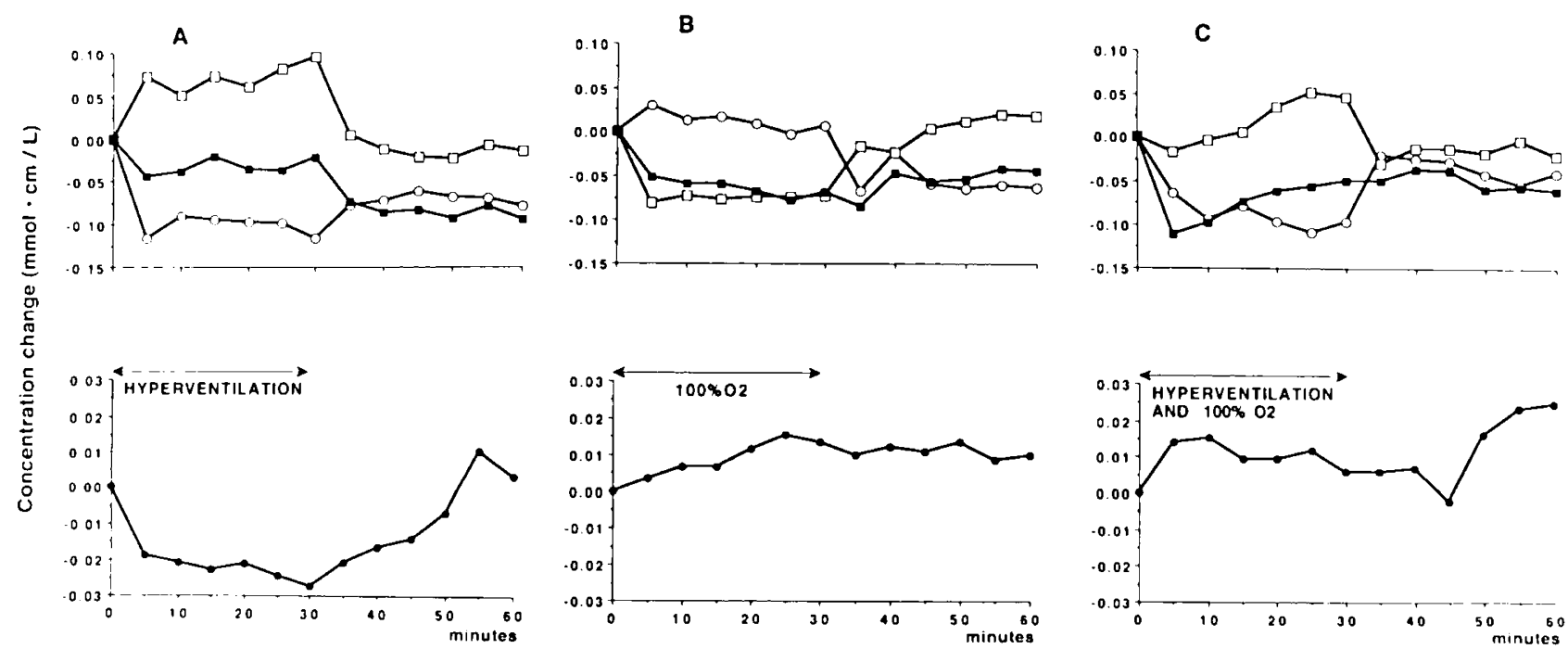

Fig. 1. Typical NIRS data for each experiment. $A$, hyperventilation; $B, 100 \% \mathrm{O}_{2}$ inhalation; and $C$, hyperventilation with $100 \% \mathrm{O}_{2}$ inhalation. O, $\mathrm{HbO}_{2} ; \square, \mathrm{HbR} ; \mathbf{\square}, \mathrm{HbT} ; \bullet, \mathrm{Cyt} a a_{3}$.

and decreased high-energy compounds was observed during severe hypocarbia $\left(\mathrm{PaCO}_{2}=1.07-1.47 \mathrm{kPa}\right)(26)$.

The present study seems to establish directly that hypocarbia causes cerebral tissue mitochondrial hypoxia (anaerobic metabolism ensuing) in newborn rabbits. Kogure et al. (27) also reported that the increased NADH/NAD ${ }^{+}$ratio in severe hypocarbia suggested stagnation of electrical flow if the metabolical impairment is in the mitochondrial system. Also, hyperventilation causes slowing of waves in an EEG, which resembles the alterations seen during hypoxemic hypoxia. Also, hyperventilation during the inhalation of hyperbaric $100 \% \mathrm{O}_{2}$ eliminates this EEG slowing (28). Moreover, the cerebral surface $\mathrm{PO}_{2}$ drops during hyperventilation but not during hyperventilation with $100 \% \mathrm{O}_{2}$ inhalation (6). In our study, Cyt $a a_{3}$ never decreased during hyperventilation with $100 \% \mathrm{O}_{2}$ inhalation, although it decreased during hyperventilation with air. Thus, metabolic abnormalities, including both brain tissue and cerebrospinal fluid lactate increases with hyperventilation with air, may be mitigated by hyperventilation during hyperbaric, hyperoxic ventilation (29, 30). Considering the decreased $\mathrm{CMRO}_{2}$, reduced oxygen de- mand, and increased anaerobic glycolysis during hyperventilation, the decrease in Cyt $a a_{3}$ may be related to an increase in aerobic glycolysis. Therefore, further studies are required to define the significance of NIRS parameters, including the neuropathologic correlation with hypocarbia (i.e. leukomalacia and/ or pontosubicular necrosis).

In conclusion, NIRS monitoring in hyperventilation provides important information on the cerebral oxygenation, blood volume, and cell metabolism in neonates. During hyperventilation with room air, NIRS demonstrated decreases in $\mathrm{HbO}_{2}, \mathrm{HbT}$, and Cyt $a a_{3}$ and an increase in HbR. On hyperventilation with $100 \%$ $\mathrm{O}_{2}$ inhalation, $\mathrm{HbO}_{2}$ and $\mathrm{HbT}$ tended to decrease more markedly but oxygenation of Cyt $a a_{3}$ remained within normal range. The reduction in cerebral oxygenation may induce ischemic brain damage. Our data demonstrated that hypocarbia results in cerebral mitochondrial hypoxia consistent with its known electroencephalographic and metabolic effects. NIRS can demonstrate the changes in the total cerebral arterial and venous blood volume, cerebral venous retention, and cerebral tissue oxygenation. In addition, anaerobic and aerobic metabolism may be 


\section{Oxyhemoglobin}

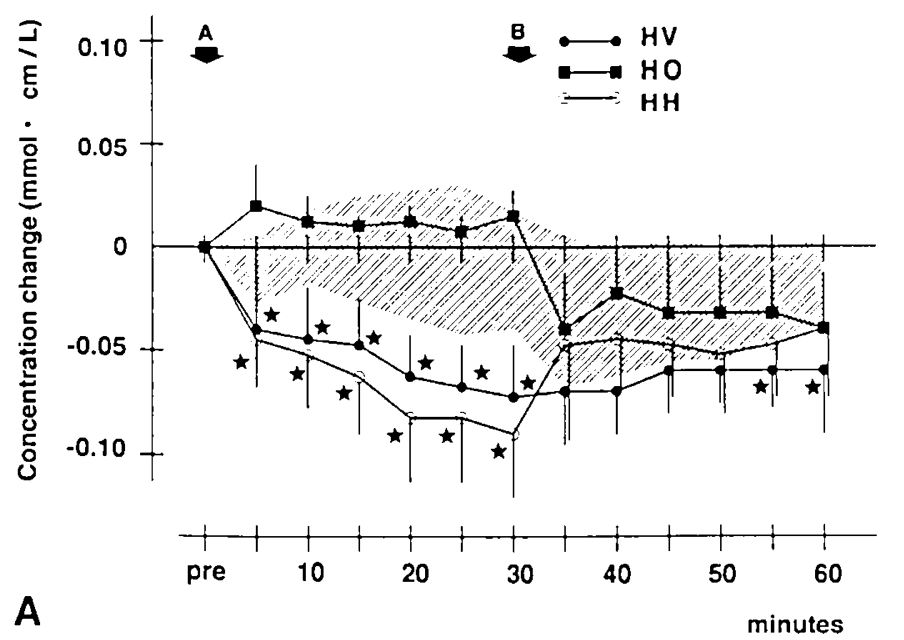

Total hemoglobin

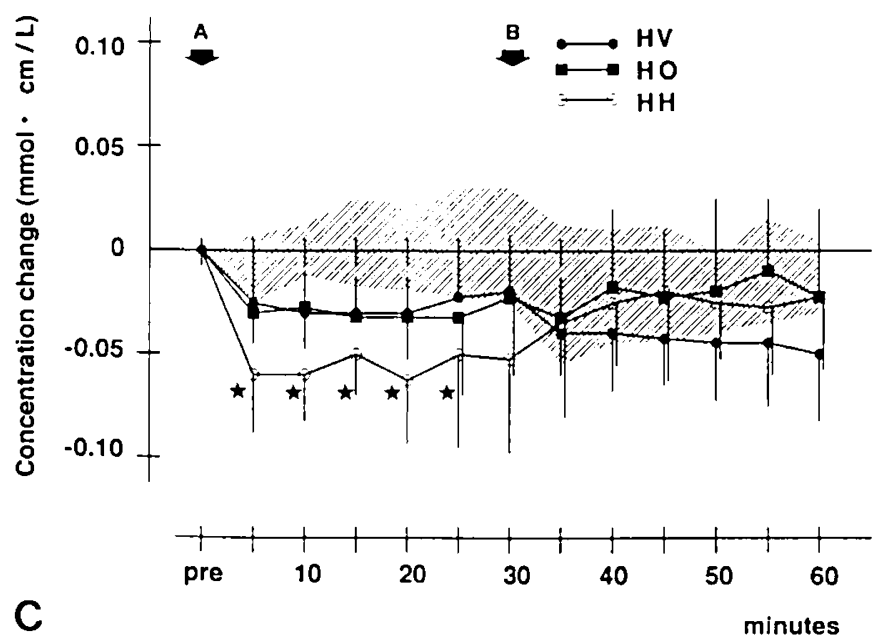

Deoxyhemoglobin

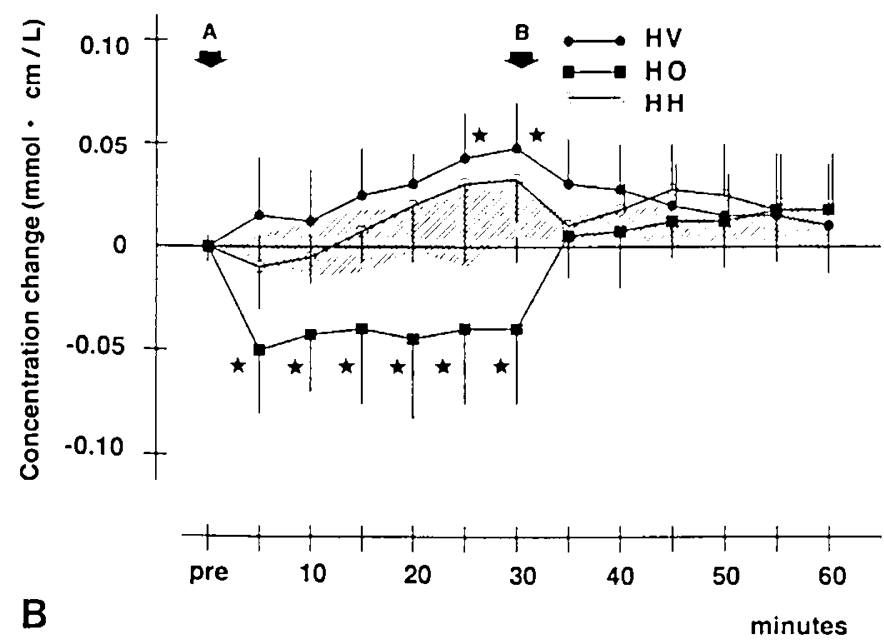

Cytochrome a, a 3

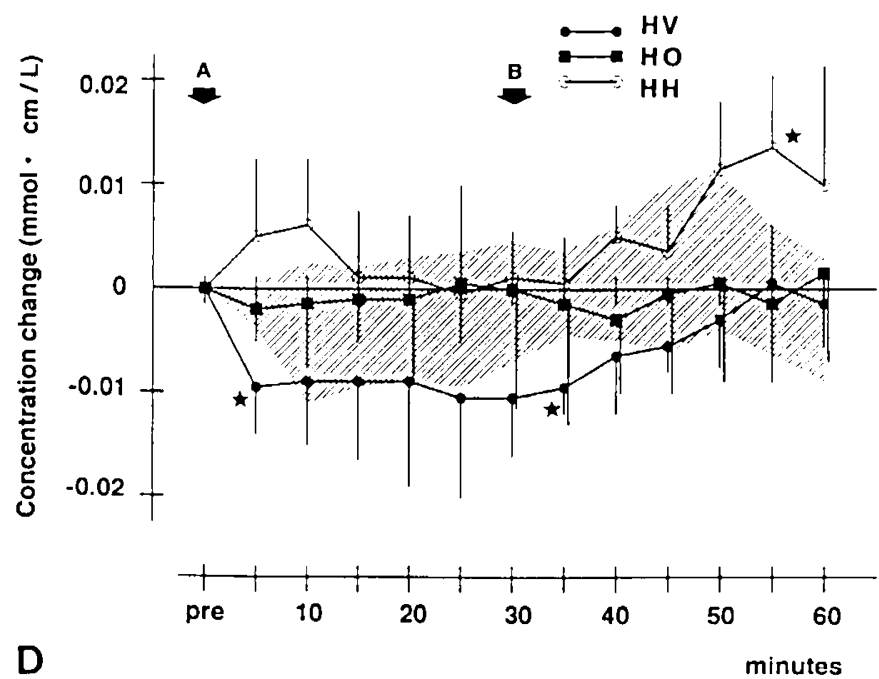

Fig. 2. Comparison of each parameter of NIRS between hyperventilation $(H V, \bullet), 100 \% \mathrm{O}_{2}$ inhalation $(H O$, $\mathbf{\square})$, and hyperventilation with $100 \% \mathrm{O}_{2}$, inhalation $(\mathrm{HH}, \mathrm{O})$. Arrows labeled $A$ and $B$ indicate starting and stopping of loading. $A$, Changes in the concentration of $\mathrm{HbO}_{2} ; B$, changes in the concentration of $\mathrm{HbR} ; C$, changes in the concentration of $\mathrm{HbT}$; and $D$, changes in the concentration of $\mathrm{Cyt} a a_{3}$. The slanted lines in each panel indicate the variation of the control (mean $\pm \mathrm{SD}$ ), and bars indicate SD. $\star$. Significantly lower than the control value, $p<0.05 ;$ MannWhitney U test.

reflected by $\mathrm{HbO}_{2}$ and Cyt $a a_{3}$ on NIRS. NIRS is available for the noninvasive monitoring of cerebral oxygenation, which may be important during hyperventilation therapy.

Acknowledgment. The authors thank Professor Tetsuro Fujiwara for his advice.

\section{REFERENCES}

1. Smith AL, Wollman H 1972 Cerebral blood flow and metabolism. Effects of anesthetic drugs and techniques. Anesthesiology 36:378-400

2. Reuter JH, Disney TA 1986 Regional cerebral blood flow and cerebral metabolic rate of oxygen during hyperventilation in the newborn dog. Pediatr Res 20:1102-1106

3. Hansen NB, Brubakk A, Bratlid D, Stonestreet BS 1984 The effects of variations in $\mathrm{PaCO}_{2}$ on brain blood flow and cardiac output in the newborn piglet. Pediatr Res 18:1132-1136

4. Kety SS, Schmidt CF 1946 The effects of active and passive hyperventilation on cerebral blood flow, cerebral oxygen consumption, cardiac output, and blood pressure of normal young men. J Clin Invest 25:107-119

5. Alberti E, Hoyer S, Hamer J, Stoeckel H, Packschiess P, Weinhardt F 1975 The effect of carbon dioxide on cerebral blood flow and cerebral metabolism in dogs. Br J Anaesth 47:941-946
6. Kennealy JA, McLennan JE, Loudon RG, McLaurin RL 1980 Hyperventilation induced cerebral hypoxia. Am Rev Respir Dis 122:407-412

7. Sugioka K, Davis DA 1960 Hyperventilation with oxygen: a possible cause of cerebral hypoxia. Anesthesiology 21:135-143

8. Wilson DF, Pastuszko A, DiGiacomo JE, Pawlowski M, Schneiderman R Delivoria-Papadopoulos M 1991 Effect of hyperventilation on oxygenation of the brain cortex of newborn piglets. J Appl Physiol 70:2691-2696

9. Calvert SA, Hoskins EM, Fong KW 1987 Etiological factors associated with the development of periventricular leukomalacia. Acta Paediatr Scand 76:254-259

10. Iida K, Takashima S, Takeuchi Y 1992 Etiologies and distribution of neonatal leukomalacia. Pediatr Neurol 8:205-209

11. Hashimoto K, Takeuchi Y, Takashima S 1991 Hypocarbia as a pathogenic factor in pontosubicular necrosis. Brain Dev 13:155-157

12. Greisen G, Munck H, Lou H 1987 Severe hypocarbia in preterm infants and neurodevelopmental deficit. Acta Paediatr Scand 76:40 1-404

13. Jöbsis FF 1977 Noninvasive infrared monitoring of cerebral and myocardial oxygen sufficiency and circulation parameters. Science 198:1264-1267

14. Wray S, Cope M, Delpy DT, Wyatt JS, Reynolds EOR 1988 Characterization of the near-infrared absorption spectra of cytochrome $a a_{3}$ and hemoglobin for the non-invasive monitoring of cerebral oxygenation. Biochim Biophys Acta 933:184-192

15. Wyatt JS, Cope M, Delpy DT, Wray S 1986 Quantification of cerebral oxygenation and hemodynamics in sick newborn infants by near-infrared spectrophotometry. Lancet 2:1063-1066 
16. Wyatt JS, Edwards AD, Cope M, Delpy DT, McCormick DC, Potter A, Reynolds EOR 1991 Response of cerebral blood volume to changes in arterial carbon dioxide tension in preterm and term infants. Pediatr Res 29:553-557

17. Tour UI 1991 Local cerebral blood flow in the newborn rabbit: an autoradiographic study of changes during development. Pediatr Res 29:517-523

18. Schade JP 1958 Maturational aspects of EEG and of spreading depression in rabbit. J Neurophysiol 22:245-257

19. Kennedy C, Grave GD, Jehle JW 1971 Effect of hyperoxia on the cerebral circulation of the newborn puppy. Pediatr Res 5:659-667

20. Kety SS, Schmidt CF 1948 The effects of altered tensions of carbon dioxide and oxygen on cerebral blood flow and cerebral oxygen consumption of normal young men. J Clin Invest 27:484-492

21. Leahy FAN, Cats D, MacCallum M, Rigatto H 1980 Effect of $\mathrm{CO}_{2}$ and $100 \%$ $\mathrm{O}_{2}$ on cerebral blood flow in preterm infants. J Appl Physiol 48:468-472

22. Rijen PC, Luyten PR, Sprenkel JWB, Kraaier V, Hufferen AC, Tulleken CAF, Hollander JA $1989^{1} \mathrm{H}$ and ${ }^{31} \mathrm{P}$ NMR measurement of cerebral lactate, highenergy phosphate levels, and $\mathrm{pH}$ in humans during voluntary hyperventilation: associated EEG, capnographic, and Doppler findings. Magn Reson Med 10:182-193
23. Scheuer J, Berry MN 1967 Effect of alkalosis on glycolysis in the isolated rat heart. Am J Physiol 213:1143-1148

24. Hansen NB, Nowicki PT, Miller RR, Malone T, Bickers RG, Menke JA 1986 Alterations in cerebral blood flow and oxygen consumption during prolonged hypocarbia. Pediatr Res 20:147-150

25. Petroff OAC, Prichard JW, Behar KL, Rothman DL, Alger JR, Shulman RG 1985 Cerebral metabolic in hyper- and hypocarbia: ${ }^{31} \mathrm{P}$ and ${ }^{1} \mathrm{H}$ nuclear magnetic resonance studies. Neurology 35:1681-1688

26. Delivoria-Papadopoulos M, Wagerle LC, Cahillane G, Goplerud JM, Mishra OP 1988 Cerebral oxygenation and membrane dysfunction following hyperventilation in newborn (NB) piglets. Pediatr Res 23:231 A(abstr)

27. Kogure K, Busto R, Matsumoto A. Scheinberg P, Reinmuth M 1975 Effect of hyperventilation on dynamics of cerebral energy metabolism. Am J Physiol 228:1862-1867

28. Reivich M, Cohen PJ, Greenbaum L 1966 Alterations in the electroencephalogram of awake man produced by hyperventilation: effects of $100 \% \mathrm{O}_{2}$ oxygen at 3 atmosphere (absolute) pressure. Neurology 16:304(abstr)

29. Plum F, Posner JB 1967 Blood and cerebrospinal fluid lactate during hyperventilation. Am J Physiol 212:864-870

30. Plum F, Posner JB, Smith WW 1968 Effect of hyperbaric-hyperoxic hyperventilation on blood, brain, and CSF lactate. Am J Physiol 215:1240-1244 